\title{
PRODUÇÃO E ATRIBUTOS DE QUALIDADE DE CULTIVARES DE MACADÂMIA NO SUDOESTE DO ESTADO DE SÃO PAULO ${ }^{1}$
}

\author{
FÁBIO ALBUQUERQUE ENTELMANN², JOÃO ALEXIO SCARPARE FILHO ${ }^{3}$, RAFAEL PIO ${ }^{4}$, \\ SIMONE RODRIGUES DA SILVA ${ }^{3}$, FILIPE BITTENCOURT MACHADO DE SOUZA ${ }^{5}$
}

RESUMO - A macadâmia apresenta-se como uma importante alternativa para a fruticultura paulista, principalmente pela sua rusticidade e pelo valor alcançado por seus frutos. No entanto, estudos relacionados ao seu desenvolvimento e às suas características produtivas e químicas são necessários para a adequada escolha da cultivar. Com o objetivo de caracterizar o desenvolvimento e a produção de diferentes cultivares de macadâmia nas condições climáticas, no sudoeste do Estado de São Paulo, foram conduzidos experimentos instalados no município de Dois Córregos-SP, nos ciclos produtivos de 2009/2010 e 2010/2011, para avaliação do ciclo fenológico da cultivar HAES-344, o desempenho produtivo, a caracterização física e o perfil de ácidos graxos das cultivares HAES-344, HAES-660, IAC 1-21, HAES-816, IAC 4-20, IAC Campinas-B, Aloha e IAC 4-12 B de macadâmia. O intumescimento de gemas ocorreu de maio a junho, a antese de final de julho a início de agosto e a queda de frutos de fevereiro a março. As cultivares HAES-344, IAC 1-21 e IAC 4-12 B apresentaram a maior produção. A cultivar HAES-816 apresentou os maiores valores para as variáveis diâmetro da casca e da amêndoa e massa da amêndoa. Para a taxa de recuperação de noz (TR), os melhores resultados foram obtidos pelas cultivares HAES-344, HAES-660 e Aloha. As cultivares HAES-660 $(68,48 \%)$, IAC 4-20 (66,88\%) e IAC 1-21 (66,76\%) apresentaram as maiores porcentagens de óleo. Todas as cultivares apresentaram em sua composição os ácidos palmitoleico, palmítico, oleico, linoleico e linolênico. Termos para Indexação: Macadamia integrifolia, amêndoa, seleção de cultivares, produtividade.

\section{PRODUCTION AND QUALITY ATTRIBUTES OF MACADAMIA TREE CULTIVARS IN THE SOUTHWEST OF SÃO PAULO STATE}

\begin{abstract}
The macadamia cultivation presents itself as an important alternative for fruit growers in São Paulo, mainly because of its rusticity and the value reached by their fruits. However, studies related to their development and their production is essential for the correct cultivar's choice. In order to characterize the development and fruit production trees for different macadamia cultivars in the southwest of São Paulo state, experiments were carried out in Dois Córregos city, in cycle's production 2009/10 and 2010/11, for evaluation of phonologic cycle HAES-344 cultivar and production, physical characteristics and fatty acids of the oil extracted from HAES-344, HAES-660, IAC 1-21, HAES-816, IAC 4-20, IAC Campinas-B, Aloha and IAC 4-12 B macadamia cultivars. The swelling of buds between May and June, the anthesis between July and August and fruit drop between February and March. HAES-344, IAC 1-21 and IAC 4-12 B cultivars had the higher production. The HAES- 816 cultivar presented the highest nut and almond values for the diameter and for the almond weight. For the kernel recovery (KR), the best results were obtained with HAES-344, HAES-660 and Aloha cultivars. HAES-660 (68,48\%), IAC 4-20 (66,88\%) and IAC 1-21 $(66,76 \%)$ cultivars had the highest percentages of oil. All cultivars showed in their composition palmitoleic, palmitic, oleic, linoleic and linolenic acids.
\end{abstract}

Index Terms: Macadamia integrifolia, almond, selection of cultivars, production.

\footnotetext{
${ }^{1}$ (Trabalho 232-13). Recebido em: 03-07-2013. Aceito para publicação em : 23-09-2013.

${ }^{2}$ Eng. Agr., D.Sc., Faculdade de Tecnologia de Itapetininga - FATEC, 18202-000, Itapetininga-SP. E-mail: fabioburi@ig.com.br ${ }^{3}$ Eng. Agr., D.Sc., Universidade de São Paulo - USP, Escola Superior de Agricultura "Luiz de Queiroz", Dep. de Produção Vegetal, Caixa Postal 09, 13418-900, Piracicaba-SP. E-mail: jascarpa@esalq.usp.br; srsilva@esalq.usp.br

${ }^{4}$ Eng. Agr., D.Sc., Universidade Federal de Lavras - UFLA, Dep. de Agricultura, Caixa Postal 3037, 37200-000, Lavras-MG. Bolsista Produtividade em Pesquisa CNPq. E-mail: rafaelpio@dag.ufla.br

${ }_{5}^{5}$ Eng. Agr., M.Sc., Discente do Programa de Pós-Graduação em Fitotecnia, Universidade Federal de Lavras - UFLA, Dep. de Agricultura, Caixa Postal 3037, 37200-000, Lavras-MG. E-mail: fbmsouza@yahoo.com.br
} 


\section{INTRODUÇÃO}

A macadâmia (Macadamia integrifólia Maiden \& Betche), originária das florestas subtropicais australianas, é, atualmente, cultivada em diversos países, a exemplo do Brasil. Essa fruteira apresenta boas perspectivas de comercialização, pois produz amêndoas características intrínsecas de alto valor agregado no mercado internacional (PIO et al., 2012). As amêndoas são consumidas desidratadas ou torradas e são utilizadas na fabricação de cosméticos e em confeitaria, sendo fonte de óleo com qualidade comparável à do azeite de oliva (SILVA et al., 2011).

No Brasil, os trabalhos de melhoramento genético com a macadâmia iniciaram-se pelo Instituto Agronômico (IAC), em 1974, que resultou no lançamento de algumas seleções para plantios comerciais (SOBIERAJSKI et al., 2006; PERDONÁ et al., 2013). Apesar das cultivares disponíveis no Estado de São Paulo, maior produtor nacional, apenas 'Aloha', 'Mauka', 'IAC Campinas-B' e 'IAC 9-20' são cultivadas em maior escala. Acredita-se que a baixa diversificação de cultivares possa estar atrelada ao fato de a exploração da macadâmia ser recente no Brasil e as informações sobre as tecnologias de cultivo estarem baseadas nos resultados de pesquisa da Austrália e Havaí (MACHADO NETO; MORYIA, 2010).

Sabe-se que a época de colheita dos frutos da macadâmia no Brasil inicia-se no mês de fevereiro (SOBIERAJSKI et al., 2007), mas se desconhece o potencial produtivo da macadâmia, necessitando-se quantificar a produção das cultivares disponíveis, para assim se obter pomares altamente tecnificados com elevada produção.

Segundo Penoni et al. (2011), há diferenças marcantes nas dimensões dos frutos e amêndoas entre as cultivares de macadâmia. Acredita-se que haja diferença significativa na constituição das amêndoas entre as diferentes cultivares, e com isso a determinação da composição química e o perfil de ácidos graxos poderiam auxiliar na escolha de cultivares que apresentem amêndoas com qualidade química superior, visando ao processamento das amêndoas ou mesmo à seleção de progenitores para programas de melhoramento genético.

Freitas e Naves (2010) analisaram a porcentagem de ácidos graxos de amêndoas e sementes comestíveis de diferentes espécies e verificaram a presença dos ácidos palmítico $(8,88 \%)$, oleico $(58,51 \%)$ e linoleico $(1,81 \%)$ em amêndoas da macadâmia. Porém, não foi destacada a procedência varietal das amêndoas que foram utilizadas nas aná- lises.

O objetivo do presente trabalho foi quantificar a produção e os atributos de qualidade de cultivares de macadâmia no sudoeste do Estado de São Paulo.

\section{MATERIAL E MÉTODOS}

Os experimentos foram realizados de maio de 2009 a março de 2011 (ciclos produtivos 2009/2010 e 2010/2011) a partir de plantas localizadas na Fazenda Palmeira, no município de Dois Córregos, sudoeste do Estado de São Paulo. Do ponto de vista climático, segundo a classificação de Köppen, o clima é mesotérmico de inverno seco, Cwa, também denominado tropical de altitude, que se caracteriza por apresentar temperatura média do mês mais frio inferior a $18^{\circ} \mathrm{C}$ e a do mês mais quente superior a $22^{\circ} \mathrm{C}$, enquanto a precipitação total do mês mais seco é inferior a 30 $\mathrm{mm}$, e a do mês mais chuvoso, $143 \mathrm{~mm}$. O solo no local do experimento foi classificado como Latossolo Vermelho-Amarelo distrófico.

Selecionou-se uma área homogênea com plantas de macadâmia com 13 anos de idade e enxertadas sobre o porta-enxerto 'Aloha', espaçadas em $8 \times 5$ metros (densidade populacional de 250 plantas $_{\text {ha }}{ }^{-1}$ ).

Para a realização da descrição fenológica da macadâmia, demarcaram-se dez plantas pertencentes à cultivar HAES-344. Em cada planta, foram realizadas observações semanais, relativas aos estádios fenológicos de floração e frutificação, em quatro quadrantes da copa. As observações foram realizadas no período de maio de 2009 a março de 2011, iniciando-se com o intumescimento das gemas, antese e, posteriormente, a queda dos frutos, de acordo com o sugerido por Sobierajski et al. (2007).

Para a quantificação da produção, demarcaram-se, na área experimental, plantas de oito cultivares de macadâmia: 'HAES-344', 'HAES660', 'IAC 1-21', 'HAES-816', 'IAC 4-20', 'IAC Campinas-B', 'Aloha' e 'IAC 4-12 B'. O delineamento utilizado foi o em blocos casualizados, no esquema fatorial dois (ciclos produtivos 2009/2010 e 2010/2011) e oito (cultivares), com seis blocos e quatro plantas por unidade experimental, sendo avaliadas apenas as duas centrais.

Durante o período produtivo dos ciclos 2009/2010 e 2010/2011, realizaram-se colheitas semanais, coletando-se frutos inteiros caídos no solo (carpelo, casca e amêndoas), que se localizavam na projeção da copa das plantas. Os frutos foram separados, descarpelados e deixados secar à temperatura ambiente até alcançarem massa constante (aproximadamente $10 \%$ de umidade). A cada colheita, con- 
tou-se o número de frutos coletados e quantificou-se sua massa. Ao final, calcularam-se a produção, o número médio de frutos, a massa média de frutos, a produtividade estimada, a taxa de recuperação de noz (TR, expressa em porcentagem, dividindo-se a massa da noz pela massa da noz em casca - noz e casca), o rendimento de amêndoas por planta e o rendimento estimado de amêndoas por hectare.

No início de abril, quando as plantas estavam em plena produção, coletaram-se amostras contendo 25 frutos inteiros de cada bloco, que constituíram as parcelas experimentais. Os frutos foram acondicionados em sacos de papel, identificados e submetidos às avaliações, utilizando-se de paquímetro digital e balança de precisão. $\mathrm{O}$ delineamento utilizado foi o em blocos casualizados, com oito tratamentos (cultivares), seis blocos e 25 frutos por unidade experimental. Foram avaliadas as dimensões do fruto (diâmetro do carpelo e amêndoa, e espessura da casca e carpelo) e a massa fresca das partes dos frutos (amêndoa, carpelo e casca).

Para a determinação do teor de óleo e o perfil de ácidos graxos, frutos das cultivares 'HAES344', 'HAES-660', 'IAC 1-21', 'HAES-816', 'IAC 4-20', 'IAC Campinas-B', 'Aloha' e 'IAC 4-12 B' foram coletados em abril de 2011, tiveram seus carpelos retirados, e as cascas separadas da amêndoa. Utilizaram-se seis plantas de cada cultivar, sendo coletados 120 frutos, que foram homogeneizados em um recipiente e, deste, resgatados 100; logo após, foram divididos em quatro repetições contendo 25 frutos cada, constituindo assim a parcela experimental. Para a extração do óleo, foram trituradas amostras de amêndoas das oito cultivares, e a extração foi realizada conforme a metodologia de Oliveira et al. (2013) e Maro et al. (2012), adaptada para amostras de $5 \mathrm{~g}$, que foram homogeneizadas em $50 \mathrm{~mL}$ de clorofórmio/metanol (2:1). A amostra homogeneizada foi filtrada em funil de separação de $250 \mathrm{~mL}$, permanecendo em repouso por 2 horas para separação física.

As amostras foram inicialmente saponificadas com solução de hidróxido de sódio/metanol 0,5 M e metiladas com solução de cloreto de amônio, metanol e ácido sulfúrico, segundo Oliveira et al. (2012) e Maro et al. (2012). Após a metilação, 5 $\mathrm{mL}$ de hexano foram adicionados à amostra, a qual foi submetida à agitação por 10 segundos. Do sobrenadante, foi retirada uma alíquota de $3 \mathrm{~mL}$, que foi concentrada com nitrogênio gasoso.

Após a extração e a esterificação do óleo, determinou-se a composição de ácidos graxos das amostras por cromatografia de fase gasosa em cromatógrafo da marca Schimadzu, modelo GC-17A, acoplado a um software para monitoramento da análise desenvolvido pela Schimadzu, segundo Oliveira et al. (2013).

As condições cromatográficas foram: temperatura inicial da coluna $40{ }^{\circ} \mathrm{C}$ por 5 minutos, aumentada a uma taxa de $10{ }^{\circ} \mathrm{C} /$ minuto até a temperatura de $140^{\circ} \mathrm{C}$, permanecendo 15 minutos, até temperatura final da coluna de $200{ }^{\circ} \mathrm{C}$, com aquecimento de $4{ }^{\circ} \mathrm{C} /$ minuto, permanecendo por $30 \mathrm{mi}-$ nutos. O gás de arraste utilizado foi o hélio, com fluxo de $1 \mathrm{~mL} /$ minuto e velocidade linear de $25 \mathrm{~cm} /$ segundo na coluna, temperatura do detector $260^{\circ} \mathrm{C}$ e temperatura do injetor $250{ }^{\circ} \mathrm{C}$. A quantidade de amostra injetada foi de 1,0 $\mu \mathrm{L}$; razão SPLIT: 100:1.

Para a identificação dos diferentes ácidos graxos, foi realizada por comparação com os tempos de retenção dos ácidos graxos da amostra com os tempos de retenção dos padrões (Supelco modelo 37 componentes FAME Mix) e, por meio de gráfico semilogarítmico do tempo de retenção com o número de carbonos, apresentados com o auxílio de ácidos graxos padrões, constituído por uma mistura de 37 ácidos graxos.

A quantificação dos ácidos graxos foi realizada por normalização interna da área do pico, sendo cada pico calculado multiplicando-se sua altura pela largura medida na metade da altura. A composição percentual de ésteres metílicos dos ácidos graxos foi obtida pela razão individual e área total, multiplicando-se por 100, considerando o fator de resposta 1.

Os resultados obtidos foram submetidos à análise de variância, a $5 \%$ de probabilidade, e ao teste de Tukey, para comparações múltiplas. As análises foram realizadas no programa computacional Sistema para Análise de Variância - SISVAR (FERREIRA, 2011).

\section{RESULTADOS E DISCUSSÃO}

De acordo com as observações realizadas, o intumescimento das gemas ocorreu expressivamente em 08/jun. em 2009 e 29/maio em 2010, para a cultivar estudada, coincidindo com a queda de temperatura. Esses dados estão de acordo com os obtidos por Sobierajsk et al. (2007), que citam que o intumescimento de gemas na região leste paulista ocorre em meados de maio e início de junho, coincidindo com a queda da temperatura.

A maior concentração de flores em antese ocorreu na primeira quinzena de agosto com o somatório de unidades térmicas variando entre 476,5 e 543,8. A queda de frutos teve início em meados de 
março, em 2010, e no início da segunda quinzena, em fevereiro de 2011, totalizando do intumescimento de gemas à queda de frutos $2.860,8$ a 3.019, 1 graus-dia (Tabela 1).

Dados semelhantes foram obtidos por Sacramento e Pereira (2003), que concluíram que, nas condições de Jaboticabal-SP, o florescimento da macadâmia ocorreu entre meados de junho e meados de setembro, e que existem variações, de um ano para outro, no período ocorrido entre o início de crescimento da inflorescência e a antese.

Quanto à produção das cultivares de macadâmia, a análise estatística revelou que não houve interação entre as cultivares e os ciclos produtivos, apenas diferença entre os fatores isolados. Comparando-se os valores médios dos dois ciclos produtivos para produção, número de frutos, produtividade estimada e rendimento de amêndoas por planta, os maiores valores foram obtidos no ciclo 2010/2011. Já para massa de frutos (sem carpelo), taxa de recuperação (TR) e rendimento de amêndoas, os valores não diferiram significativamente de um ciclo produtivo para outro (Tabela 2), o que era esperado, uma vez que esses parâmetros são intrínsecos à cultivar.

Quanto às cultivares, os maiores valores de produção foram obtidos com as cultivares HAES344, IAC 1-21 e IAC 4-12 B, onde se obteve produção entre 18,06 e 20,62 kg por planta. Essas cultivares também se destacaram das demais, em relação ao número médio de frutos, produtividade estimada e rendimento de amêndoas (Tabela 2). Os valores obtidos de produção foram superiores aos registrados por Pio et al. (2012), que obtiveram produção de 9,46 kg por planta com a cultivar HAES-344 em Itapira-SP.

Para a massa média de frutos, a cultivar IAC 1-21 destacou-se das demais. Os maiores valores para a taxa de recuperação de noz (TR) foram obtidos pelas cultivares HAES-344, HAES-660 e Aloha. Os menores valores, para as características estudadas, foram obtidos com a cultivar HAES-816. Esses resultados estão de acordo com os obtidos por Penoni et al. (2011), que observaram que há diferença entre a massa das amêndoas e a taxa de recuperação de noz entre cultivares de macadâmia.

Quanto às dimensões dos frutos, a análise estatística demonstrou que os maiores diâmetros do carpelo e da amêndoa foram obtidos a partir da cultivar HAES-816, diferindo estatisticamente apenas das cultivares HAES-660 e IAC 4-20, que apresentaram os menores valores para esses parâmetros (Tabela 3). A espessura da casca foi maior na cultivar IAC Campinas-B e menor na cultivar IAC 1-21. Quanto à espessura do carpelo, diferiram estatisticamente as cultivares Aloha (maior) e IAC Campinas-B (menor).
A cultivar HAES-816 destacou-se também das outras cultivares em características relativas às massas da amêndoa e do carpelo, no entanto para a massa da casca, o maior valor foi obtido com a cultivar IAC 1-21 (Tabela 3). Apesar de os maiores valores de massa e diâmetro terem sido obtidos pela cultivar HAES-816, essa relação não ocorreu nas demais cultivares. Semelhantes resultados foram obtidos por Penoni et al. (2011) que, trabalhando com outras cultivares, verificaram a falta de sincronia entre a dimensão e a massa da amêndoa.

A cultivar HAES-816 apresentou os maiores valores da espessura de casca e massa da amêndoa. Como essa espécie tem seus porta-enxertos propagados via seminífera (DALASTRA et al., 2010), amêndoas de maiores dimensões e massas podem acelerar o processo de produção de mudas devido à maior quantidade de substâncias de reservas, um dos entraves da cadeia produtiva da macadâmia.

Para a quantificação do teor de óleo e perfil de ácidos graxos, pode-se perceber que o maior teor de óleo foi obtido pela cultivar HAES-660, porém não diferindo das cultivares IAC 4-20 e IAC 1-21 (Tabela 4). Para essas cultivares, os valores obtidos para o extrato etéreo está na faixa citada por Venkatachalam e Sathe (2006), que relataram que as amêndoas da macadâmia possuem em torno de $66 \%$ de óleo.

Kaijser et al. (2000) encontraram valores de óleo entre $69 \%$ e $78 \%$ em diferentes cultivares de macadâmias produzidas em diferentes regiões da Nova Zelândia, mostrando que o teor de óleo pode variar para mesmas cultivares em diferentes regiões. Maro et al. (2012) citam que o teor de óleo é altamente influenciado pela cultivar.

Todas as cultivares apresentaram em sua composição os ácidos palmitoleico, palmítico, oleico, linoleico e linolênico (Tabela 4). Para as condições do sudoeste paulista, a cultivar que apresentou a maior quantidade de ácido palmitoleico foi a HAES-344 (19,97). No entanto, Maro et al. (2012) detectaram 29,64\% de ácido palmitoleico na cutivar Édson, em macadâmias produzidas no leste paulista. Porém, os valores encontrados por Maro et al. (2012) na cultivar HAES-344 são próximos aos obtidos no presente trabalho.

Quanto ao ácido palmítico, os maiores teores foram registrados nas cultivares IAC 1-21, IAC 4-12 B e HAES-816, um pouco superior ao relatado por Freitas e Neves (2010) (8,88\%). Por esses resultados, salienta-se que há diferença entre os teores de ácidos graxos entre as cultivares.

Outra característica importante relacionada a maiores teores de ácido oleico é a resistência à oxidação (rancificação), em relação aos ácidos gra- 
xos poli-insaturado. A cultivar Aloha apresentou o maior teor para esse ácido graxo. $\mathrm{O}$ ácido oleico é uma gordura monoinsaturada que está presente em grandes quantidades no azeite de oliva. Ressalta-se que os teores de ácido oleico encontrados nessas cultivares estão em níveis superiores em comparação aos teores encontrados por Oliveira et al. (2012) em frutos das oliveiras Arbequina (61,30\%) e Grappolo $561(61,78 \%)$. Por esses resultados, verifica-se a importância de se conhecer o perfil dos ácidos graxos nas diferentes cultivares.

Já os ácidos linoleico e linolênico contribuem para o aumento da oxidação do óleo, sendo, portanto, desejados em menor teor.

TABELA 1- Data e somatório graus-dia (SGD) para estádios fenológicos da macadâmia HAES-344 no sudoeste paulista, nos ciclos produtivos de 2009/2010 e 2010/2011.

\begin{tabular}{ccccccc}
\hline \multirow{2}{*}{ Ciclos } & \multicolumn{4}{c}{ Fenofases } \\
& \multicolumn{2}{c}{ Gemas intumescidas } & \multicolumn{2}{c}{ Antese } & \multicolumn{2}{c}{ Queda de frutos } \\
\hline \multirow{2}{*}{$2009 / 2010$} & Data & SGD & Data & SGD & Data & SGD \\
$2010 / 2011$ & $29 /$ maio & 0 & $08 /$ ago. & 476,5 & $06 /$ mar. & $3.019,1$ \\
\hline
\end{tabular}

TABELA 2- Produção (P, kg), número médio de frutos (NF), massa média da amêndoa ( $\mathrm{M}, \mathrm{g})$, produtividade estimada $\left(\mathrm{PE}, \mathrm{t} \mathrm{ha}^{-1}\right)$, taxa de recuperação de noz $(\mathrm{TR}, \%)$, rendimento de amêndoa por planta $\left(\mathrm{RA}, \mathrm{kg}\right.$ planta $\left.\mathrm{a}^{-1}\right)$ e rendimento estimado de amêndoa por hectare $\left(\mathrm{RAH}, \mathrm{t} \mathrm{ha}^{-1}\right)$ de oito cultivares de macadâmia no sudoeste paulista, nos ciclos produtivos de 2009/2010 e 2010/2011.

\begin{tabular}{cccccccc}
\hline Cultivares & $\begin{array}{c}\mathrm{P} \\
(\mathrm{kg})^{(1)}\end{array}$ & $\mathrm{NF}$ & $\begin{array}{c}\mathrm{M} \\
(\mathrm{g})\end{array}$ & $\begin{array}{c}\mathrm{PE} \\
\left(\mathrm{t} \mathrm{ha}^{-1}\right)\end{array}$ & $\begin{array}{c}\mathrm{TR} \\
(\%)\end{array}$ & $\begin{array}{c}\text { RA } \\
\left(\mathrm{kg} \mathrm{planta}^{-1}\right)\end{array}$ & $\begin{array}{c}\text { RAH } \\
(\mathrm{t} \mathrm{ha})^{-1}\end{array}$ \\
\hline HAES-344 & $20,62 \mathrm{a}$ & $2.749,89 \mathrm{a}$ & $7,50 \mathrm{c}$ & $5,15 \mathrm{a}$ & $23,81 \mathrm{a}$ & $4,91 \mathrm{a}$ & $1,22 \mathrm{a}$ \\
IAC 1-21 & $19,77 \mathrm{ab}$ & $2.326,47 \mathrm{abc}$ & $8,50 \mathrm{a}$ & $4,94 \mathrm{ab}$ & $22,4 \mathrm{bc}$ & $4,46 \mathrm{bc}$ & $1,11 \mathrm{ab}$ \\
IAC 4-12 B & $18,06 \mathrm{abc}$ & $2.463,18 \mathrm{ab}$ & $7,33 \mathrm{c}$ & $4,51 \mathrm{abc}$ & $22,46 \mathrm{bc}$ & $4,05 \mathrm{abc}$ & $1,01 \mathrm{abc}$ \\
IAC Campinas-B & $16,87 \mathrm{bcd}$ & $2.154,46 \mathrm{bcd}$ & $7,83 \mathrm{~b}$ & $4,22 \mathrm{bcd}$ & $22,63 \mathrm{~b}$ & $3,82 \mathrm{bc}$ & $0,95 \mathrm{bc}$ \\
IAC 4-20 & $15,41 \mathrm{~cd}$ & $2.150,81 \mathrm{bcd}$ & $7,17 \mathrm{~d}$ & $3,85 \mathrm{~cd}$ & $21,60 \mathrm{c}$ & $3,32 \mathrm{~cd}$ & $0,82 \mathrm{~cd}$ \\
HAES-660 & $14,79 \mathrm{~cd}$ & $1.972,77 \mathrm{~cd}$ & $4,50 \mathrm{c}$ & $3,70 \mathrm{~cd}$ & $23,90 \mathrm{a}$ & $3,53 \mathrm{~cd}$ & $0,88 \mathrm{~cd}$ \\
Aloha & $14,75 \mathrm{~cd}$ & $2.159,39 \mathrm{bcd}$ & $6,83 \mathrm{~d}$ & $3,69 \mathrm{~cd}$ & $23,53 \mathrm{a}$ & $3,46 \mathrm{~cd}$ & $0,86 \mathrm{~cd}$ \\
HAES-816 & $13,93 \mathrm{~d}$ & $1.817,54 \mathrm{~d}$ & $7,67 \mathrm{c}$ & $3,48 \mathrm{~d}$ & $20,26 \mathrm{~d}$ & $2,82 \mathrm{~d}$ & $0,70 \mathrm{~d}$ \\
Ciclos produtivos & & & & & & & \\
2009/10 & $15,68 \mathrm{~b}$ & $2.077,19 \mathrm{~b}$ & $7,53 \mathrm{a}$ & $3,92 \mathrm{~b}$ & $22,59 \mathrm{a}$ & $3,55 \mathrm{~b}$ & $0,88 \mathrm{a}$ \\
2010/11 & $17,95 \mathrm{a}$ & $2.383,22 \mathrm{a}$ & $7,54 \mathrm{a}$ & $4,49 \mathrm{a}$ & $22,61 \mathrm{a}$ & $4,06 \mathrm{a}$ & $1,01 \mathrm{a}$ \\
CV (\%) & 16,69 & 16,46 & 9,52 & 16,67 & 3,10 & 17,58 & 17,64 \\
\hline
\end{tabular}

(1) Médias seguidas de letras iguais, na coluna, não diferem pelo teste de Tukey, a $5 \%$ de probabilidade. 
TABELA 3- Dimensões de fruto (diâmetro do carpelo e amêndoa, espessura da casca e carpelo) e massa das partes do fruto (amêndoa, carpelo e casca) de oito cultivares de macadâmia no sudoeste paulista.

\begin{tabular}{cccccccc}
\hline & \multicolumn{4}{c}{ Dimensões $(\mathrm{mm})$} & \multicolumn{3}{c}{ Massa das partes do fruto $(\mathrm{g})$} \\
Cultivar & $\begin{array}{c}\text { Diâmetro } \\
\text { Carpelo }^{(1)}\end{array}$ & $\begin{array}{r}\text { Diâmetro } \\
\text { amêndoa }\end{array}$ & $\begin{array}{c}\text { Espessura } \\
\text { Casca }\end{array}$ & $\begin{array}{c}\text { Espessura } \\
\text { Carpelo }\end{array}$ & Amêndoa & Carpelo & Casca \\
\hline HAES-344 & $23,50 \mathrm{ab}$ & $18,30 \mathrm{ab}$ & $2,30 \mathrm{abc}$ & $2,08 \mathrm{ab}$ & $4,40 \mathrm{~b}$ & $2,70 \mathrm{abcd}$ & $5,82 \mathrm{c}$ \\
IAC 1-21 & $23,02 \mathrm{ab}$ & $18,60 \mathrm{ab}$ & $2,10 \mathrm{c}$ & $2,08 \mathrm{ab}$ & $4,03 \mathrm{~b}$ & $2,50 \mathrm{bcd}$ & $6,47 \mathrm{a}$ \\
IAC 4-12 B & $23,01 \mathrm{ab}$ & $18,02 \mathrm{~b}$ & $2,20 \mathrm{bc}$ & $2,15 \mathrm{ab}$ & $4,16 \mathrm{~b}$ & $2,76 \mathrm{ab}$ & $5,57 \mathrm{~d}$ \\
IAC Campinas-B & $23,30 \mathrm{ab}$ & $18,60 \mathrm{ab}$ & $2,71 \mathrm{a}$ & $1,73 \mathrm{~b}$ & $4,57 \mathrm{~b}$ & $2,26 \mathrm{~d}$ & $6,14 \mathrm{~b}$ \\
IAC 4-20 & $22,22 \mathrm{~b}$ & $18,11 \mathrm{~b}$ & $2,33 \mathrm{abc}$ & $1,86 \mathrm{ab}$ & $4,26 \mathrm{~b}$ & $2,73 \mathrm{~cd}$ & $5,48 \mathrm{~d}$ \\
HAES-660 & $22,40 \mathrm{~b}$ & $16,51 \mathrm{c}$ & $2,41 \mathrm{abc}$ & $2,05 \mathrm{ab}$ & $4,31 \mathrm{~b}$ & $2,30 \mathrm{~cd}$ & $5,80 \mathrm{c}$ \\
Aloha & $23,10 \mathrm{ab}$ & $17,81 \mathrm{bc}$ & $2,52 \mathrm{ab}$ & $2,25 \mathrm{a}$ & $4,00 \mathrm{~b}$ & $2,30 \mathrm{~cd}$ & $5,29 \mathrm{e}$ \\
HAES-816 & $24,60 \mathrm{a}$ & $19,70 \mathrm{a}$ & $2,20 \mathrm{bc}$ & $2,15 \mathrm{ab}$ & $5,95 \mathrm{a}$ & $2,96 \mathrm{a}$ & $6,11 \mathrm{~b}$ \\
C.V. $(\%)$ & 4,27 & 4,92 & 8,21 & 12,11 & 9,57 & 9,31 & 10,97 \\
\hline
\end{tabular}

(1) Médias seguidas de letras iguais, na coluna, não diferem pelo teste de Tukey, a 5\% de probabilidade.

TABELA 4- Teor de óleo e perfil de ácidos graxos em amêndoas de oito cultivares de macadâmia cultivadas no sudoeste paulista.

\begin{tabular}{cccccccc}
\hline \multirow{2}{*}{ Cultivar } & \multicolumn{1}{c}{$\begin{array}{c}\text { Ácidos Graxos (\%) } \\
(\%))^{(1)}\end{array}$} & $\begin{array}{c}\text { Palmitoléico } \\
(\omega-7)\end{array}$ & Palmítico & $\begin{array}{c}\text { Oléico } \\
(\omega-9)\end{array}$ & $\begin{array}{c}\text { Linoléico } \\
(\omega-6)\end{array}$ & $\begin{array}{c}\text { Linolênico } \\
(\omega-3)\end{array}$ & $\begin{array}{c}\text { Ácidos Graxos } \\
\text { (2) }\end{array}$ \\
\hline HAES-344 & $65,30 \mathrm{~b}$ & $19,97 \mathrm{a}$ & $8,63 \mathrm{ab}$ & $59,59 \mathrm{~b}$ & $1,06 \mathrm{~b}$ & $0,12 \mathrm{a}$ & $12,63 \mathrm{a}$ \\
IAC 1-21 & $66,76 \mathrm{ab}$ & $13,49 \mathrm{~d}$ & $9,96 \mathrm{a}$ & $61,88 \mathrm{~b}$ & $2,77 \mathrm{a}$ & $0,08 \mathrm{a}$ & $11,82 \mathrm{ab}$ \\
IAC 4-12 B & $65,51 \mathrm{~b}$ & $17,99 \mathrm{~b}$ & $9,22 \mathrm{a}$ & $60,82 \mathrm{~b}$ & $1,58 \mathrm{ab}$ & $0,13 \mathrm{a}$ & $10,26 \mathrm{~b}$ \\
IAC Campinas-B & $65,48 \mathrm{~b}$ & $15,63 \mathrm{c}$ & $8,64 \mathrm{ab}$ & $61,62 \mathrm{~b}$ & $2,30 \mathrm{a}$ & $0,14 \mathrm{a}$ & $11,67 \mathrm{ab}$ \\
IAC 4-20 & $66,88 \mathrm{ab}$ & $15,89 \mathrm{c}$ & $8,10 \mathrm{ab}$ & $63,83 \mathrm{ab}$ & $1,30 \mathrm{ab}$ & $0,11 \mathrm{a}$ & $10,77 \mathrm{~b}$ \\
HAES-660 & $68,48 \mathrm{a}$ & $15,40 \mathrm{c}$ & $7,43 \mathrm{~b}$ & $63,34 \mathrm{ab}$ & $1,25 \mathrm{ab}$ & $0,12 \mathrm{a}$ & $12,46 \mathrm{a}$ \\
Aloha & $66,38 \mathrm{~b}$ & $10,89 \mathrm{e}$ & $8,36 \mathrm{ab}$ & $66,50 \mathrm{a}$ & $2,40 \mathrm{a}$ & $0,11 \mathrm{a}$ & $11,74 \mathrm{ab}$ \\
HAES-816 & $66,14 \mathrm{~b}$ & $15,60 \mathrm{c}$ & $9,07 \mathrm{a}$ & $62,88 \mathrm{ab}$ & $1,56 \mathrm{ab}$ & $0,14 \mathrm{a}$ & $10,75 \mathrm{~b}$ \\
C.V. $(\%)$ & 14,45 & - & - & - & - & - & - \\
\hline
\end{tabular}

(1) Médias seguidas de letras iguais, na coluna, não diferem pelo teste de Tukey, a $5 \%$ de probabilidade.

(2) Ácidos Graxos Não Identificados (NI).

Todas as cultivares apresentaram em sua composição os ácidos palmitoleico, palmítico, oleico, linoleico e linolênico.

\section{CONCLUSÕES}

O intumescimento de gemas ocorreu entre maio e junho, a antese entre julho e agosto e a queda de frutos entre fevereiro e março. As cultivares HAES-344, IAC 1-21 e IAC 4-12 B apresentam a maior produção. A cultivar HAES-816 apresenta os maiores valores para as variáveis diâmetro do carpelo e da amêndoa e massa da amêndoa. Para a taxa de recuperação de noz (TR), os melhores resultados são obtidos pelas cultivares HAES344, HAES-660 e Aloha. As cultivares HAES660, IAC 4-20 e IAC 1-21 apresentam as maiores porcentagens de óleo.

\section{AGRADECIMENTOS}

Ao Conselho Nacional de Desenvolvimento Científico e Tecnológico (CNPq), pelo auxílio financeiro à Empresa QueenNut Macadâmia pela concessão da área para a execução da pesquisa, e as amostras de amêndoas para a determinação do perfil de ácidos graxos. 


\section{REFERÊNCIAS}

DALASTRA, I.M.; PIO, R.; ENTELMANN, F.A.; WERLE, T.; ULIANA M.B.; SCARPARE FILHO, J.A. Germinação de sementes de nogueiramacadâmia submetidas à incisão e embebição em ácido giberélico. Ciência e Agrotecnologia, Lavras, v.34, n.3, p.641-645, 2010.

FERREIRA, D.F. Sisvar: a computer statistical analysis system. Ciência e Agrotecnologia, Lavras, v.35, n.6, p.1.039-1.042, 2011.

FREITAS, J.B.; NAVES, M.M.V. Composição química de nozes e sementes comestíveis e sua relação com a nutrição e saúde. Revista Nutrição, Campinas, v.23, n.2, p.269-279, 2010.

KAIJSER, A.; DUTTA, P.; SAVAGE, G. Oxidative stability and lipid composition of macadamia nuts grown in New Zealand. Food Chemistry, London, v.71, n.1, p.67-70, 2000.

MACHADO NETO, N.B.; MORYIA, A.T. Variability in Macadamia integrifolia by RAPD markers. Crop Breeding and Applied Biotechnology, Londrina, v.10, n.3, p.266-270, 2010 .

MARO, L.A.C.; PIO, R.; PENONI, E.S.; OLIVEIRA, M.C.; PRATES, F.C.; LIMA, L.C.O.; CARDOSO, M.G. Caracterização química e perfil de ácidos graxos em cultivares de nogueiramacadâmia. Ciência Rural, Santa Maria, v.42, n.12, p.2.166-2.171, 2012.

OLIVEIRA, M.C.; PIO, R.; RAMOS, J.D.; LIMA, L.C.O.; PASQUAL, M.; SANTOS, V.A. Fenologia e características físico-químicas de frutos de abacateiros visando à extração de óleo. Ciência Rural, Santa Maria, v.43, n.3, p.411-418, 2013.

OLIVEIRA, M.C.; RAMOS, J.D.; PIO, R.; CARDOSO, M.G. Características fenológicas e físicas e perfil de ácidos graxos em oliveiras no sul de Minas Gerais. Pesquisa Agropecuária Brasileira, Brasília, v.47, n.1, p.30-35, 2012.

PENONI, E.S.; PIO, R.; RODRIGUES, F.A.; MARO, L.A.C.; COSTA, F.C. Análise de frutos e nozes de cultivares de nogueira-macadâmia. Ciência Rural, Santa Maria, v.41, n.12, p.20802083, 2011.
PERDONÁ, M.J.; MARTINS, A.N.; SUGUINO, E.; SORATTO, R.P. Crescimento e produtividade de nogueira-macadâmia em consórcio com cafeeiro arábica irrigado. Pesquisa Agropecuária Brasileira, Brasília, v.47, n.11, p. 1613-1620, 2012.

PIO, R.; PENONI, E.S.; RODRIGUES, F.A.; RAMOS, J.D.; DECARLOS NETO, A. Produção e amplitude de colheita de cultivares de nogueiramacadâmia em Itapira, São Paulo. Revista Ceres, Viçosa, MG, v.59, n.6, p.826-831, 2012.

SACRAMENTO, C.K.; PEREIRA, F.M. Fenologia da floração da nogueira-macadâmia (Macadamia integrifolia Maiden \& Betche) nas condições climáticas de Jaboticabal, São Paulo, Brasil. Revista Brasileira de Fruticultura, Jaboticabal, v.25, n.1, p.19-22, 2003.

SILVA, F.A.; GONÇALVES, L.A.G.; DAMIANI, C.; GONÇALVES, M.A.B.; SOARES JÚNIOR, M.S.; MARSAIOLI JÚNIOR, A. Estabilidade oxidativa de amêndoas de noz macadâmia secas por micro-ondas com ar quente. Pesquisa Agropecuária Tropical, Goiânia, v. 41, n. 2, p. 286-292, 2011.

SOBIERAJSKI, G.R.; BARBOSA, W.; BETTIOL NETO, J.E.; CHAGAS, E.A.; CAMPO DALL'ORTO, F.A. Caracterização dos estágios fenológicos em sete cultivares e seleções de nogueira-macadâmia. Revista Brasileira de Fruticultura, Jaboticabal, v.29, n.3, p.690-694, 2007.

VENKATACHALAM, M; SATHE, S.K. Chemical composition of selected edible nut seeds. Journal of Agricultural and Food Chemistry, Easton, v.54, n.13, p.4.705-4.714, 2006. 